\title{
RETRACTED ARTICLE: Trust and conditionality; Or, can the World Bank 'Leopard' change its spots?
}

\section{Paul Mosley}

Received: 1 September 2010 /Revised: 17 January 2011 / Accepted: 8 February 2011 /

Published online: 23 March 2011

(C) Springer Science+Business Media, LLC 2011

The article was published Online First, but is withdrawn due to copyright violation.

The article was published Online First, but is withdrawn due to copyright violation.

P. Mosley $(\bowtie)$

Department of Economics, University of Sheffield, 9 Mappin St., Sheffield,

South Yorkshire S1 4DT, UK

e-mail: p.mosley@sheffield.ac.uk 